\title{
POR UMA CONTEXTUALIZAÇÃO DOS TERMOS "RAÇA" E "ETNIA" A PARTIR DE PERSPECTIVAS BIOLÓGICAS, SOCIOLÓGICAS E DO DIREITO INTERNACIONAL
}

\author{
Cláudia Regina de Oliveira Magalhães da Silva Loureiro ${ }^{1}$ \\ Anna Caramuru Pessoa Aubert ${ }^{2}$
}

\begin{abstract}
RESUMO: Nosso artigo objetiva (i) traçar, a partir de metodologia hipotético-dedutiva, um histórico da construção da ideia de que existem raças dentro da espécie humana, e (ii) verificar, na prática, como se deu e se dá a construção social e cultural da raça, por meio de uma análise, primeiro, do regime jurídico de Direito Internacional dos Direitos Humanos relativos às raças e, segundo, a partir de uma análise do caso Ellwanger. Ao final, esperamos que nossa pesquisa contribua com a expansão do campo dos estudos críticos raciais, ao contextualizar a expressão "raça", seja historicamente, seja no campo do direito internacional. Palavras-chave: Raça; Etnia; Direito Internacional; Caso Ellwanger; Racismo.
\end{abstract}

\section{FOR A CONTEXTUALIZATION OF THE TERMS "RACE" AND "ETHNICITY" FROM BIOLOGICAL, SOCIOLOGICAL AND INTERNATIONAL LAW PERSPECTIVES}

\begin{abstract}
Our article aims to (i) trace, using a hypothetical-deductive methodology, a history of the construction of the idea that there are races within the human species, and (ii) verify, in practice, how the social and cultural construction of race took and takes place, through an analysis, first, of the legal regime of the International Human Rights Law relating to races and, second, by analysing the Ellwanger case. In the end, we hope that our research contributes to the expansion of the field of critical racial studies, by contextualizing the expression "race", both historically and in the field of international law.
\end{abstract}

Keywords: Race; Ethnicity; International Law; Ellwanger case; Racism.

\section{INTRODUÇÃO}

A partir de metodologia hipotético-dedutiva e de revisão bibliográfica, a finalidade do presente artigo é situar os conceitos de raça e etnia, diferenciando entre seus aspectos biológicos e sociológicos e, com isso, pretendemos tornar os debates em torno do racismo mais claros e adequados.

\footnotetext{
${ }^{1}$ Professora Adjunta na Universidade Federal de Uberlândia. Pós-doutora em Direitos Humanos pela Faculdade de Direito da Universidade de Coimbra. Doutora pela Pontifícia Universidade Católica de São Paulo. E-mail: crmloureiro@gmail.com. Orcid: https://orcid.org/0000-0002-0471-5711. Lattes: http://lattes.cnpq.br/8808192737927290.

2 Doutoranda em Direito da Universidade Federal do Rio de Janeiro (UFRJ), Mestre em Direito Constitucional pela Pontifícia Universidade Católica de São Paulo, e Pós-graduada em Direitos Animais pela Universidade de Lisboa. E-mail: annacaramurup@gmail.com. Orcid: https://orcid.org/0000-0003-4442-6217. Lattes: http://lattes.cnpq.br/2005170752734528.
} 
Para este fim, na primeira parte do artigo, apresentaremos um recorte histórico sobre a construção da existência de raças humanas, utilizando-nos, para este fim, dos trabalhos de Keith Thomas e Francisco Bethencourt, e dialogando com autores no âmbito dos estudos críticos raciais. Trabalharemos, ainda, com as ideias desumanização e animalização, como teorizadas por David Livingstone Smith, e verificaremos, a partir das exposições de indivíduos considerados exóticos em zoológicos humanos, como isso se apresentou, em diversas situações, no passado.

Na segunda parte do artigo, analisaremos o modo como o regime jurídico de Direito Internacional dos Direitos Humanos lida com a questão racial, e apresentaremos, como aspecto prático do embate entre as noções de raça e etnia - considerando, aqui, que a existência de mais de uma raça dentro da espécie humana foi refutada, em definitivo, pelo sequenciamento do genoma humano -, uma análise do caso Ellwanger, julgado pelo Supremo Tribunal Federal em 2003, no HC 82.424-2, do Rio Grande do Sul. Trabalharemos, nesse ponto, com o parecer, sobre o caso, de Celso Lafer.

\section{TAXONOMIAS DE RAÇA E ESPÉCIE}

\subsection{Desumanização}

Quando criança, a escritora Maya Angelou morava em Stamps, no sul segregacionista dos Estados Unidos, com sua avó, a quem ela chamava Momma.

Certa ocasião, acometida por uma dor de dente aguda, teve que ser levada às pressas ao dentista, e Momma sentiu que caminhar com a neta até o consultório mais distante - que ficava em outra cidade, a aproximadamente quarenta quilômetros de distância - seria uma tarefa árdua demais, de modo que optou por buscar o dentista mais próximo, que atendia apenas brancos.

Durante a Grande Depressão, contudo, a avó de Walker, proprietária de um mercado no coração da área dos negros, havia emprestado dinheiro para muitos brancos, dentre os quais esse dentista. E ela acreditou que, com isso, ele se disporia, em retribuição ao favor, a atender sua neta. Não foi o que aconteceu. O dentista recusou as súplicas veementemente, alegando que preferiria colocar as mãos dentro da boca de um cachorro, do que na de um negro (nigger) (ANGELOU, 1969). 
O mundo pós-segregação racial não encerrou, como o fim da escravização de negros africanos nas Américas não havia, tampouco, encerrado, o racismo estrutural e as violências dele decorrentes. Grada Kilomba, em seu livro Plantation Memories: Episodes of Everyday Racism (2010), apresenta diversos relatos de racismos cotidianos do mundo contemporâneo. Aqui, traremos apenas um, que interessa, especialmente, ao presente artigo:

Eu tive um breve relacionamento com um homem (branco), nada sério... e um dia ele estava cheirando meu cabelo e disse: "Nossa, seu cabelo tem cheiro de coco..." E então ele começou a cantar a seguinte música: 'Die Affen rasen durch den Wald, der eine machte den anderen kalt. Wer hat die Kokosnuss geklaut?' Você conhece aquela música alemã? [...] E ele cantou essa música, e eu fiquei tão... tão... e ele disse: "Mas seu cabelo tem cheiro de creme de coco!" Ele cheirou meu cabelo e fez essa associação... com macacos, macacos na selva que roubaram cocos...Você entende? Ele me associou a macacos... e essa música... Eu fique destruída..." (KILOMBA, 2010, p. 74, tradução nossa)

Tal qual ocorreu com Angelou, o relato de Kilomba nos coloca em contato com o que David Livingstone Smith (2011) convencionou chamar "desumanização", um fenômeno que ocorre primeiro em nossas mentes e, em seguida, se exterioriza na esfera da realidade, é dizer: por meio da desumanização de alguém, nos tornamos capazes de praticar atrocidades que tornam este indivíduo, ao final do processo, algo. Trata-se de mecanismo, nessa medida, que afasta possíveis incômodos morais, facilitando a prática de atos cruéis.

E esse processo, como se verifica nos dois exemplos apresentados, frequentemente é associado à animalização, ou seja, na mesma medida em que percebemos alguém como mais animal, o enxergamos como menos humano e, consequentemente, como menos merecedor de consideração moral, já que "é errado matar uma pessoa, mas é permissível exterminar um rato" (SMITH, 2011, p. 119, tradução nossa).

De um modo um pouco diverso, Zakiyyah Iman Jackson sustenta que "o reconhecimento da pessoalidade ou da humanidade não anula a animalização da negritude" (JACKSON, 2020, p. 18, tradução nossa) e, para a autora, negros sempre foram identificados como humanos, mesmo que de um modo reduzido, e isso por si só comprova que sua assimilação na categoria de "humanidade universal" não pode ser equiparada a uma libertação, já que essa assimilação é, no fundo, o modus operandi da tradição racista. Negros não foram, nesse sentido, excluídos da categoria de humanos, mas, diversamente, tiveram sua humanidade "apropriada, invertida e, em última análise, plasticizada por uma animalização depreciativa" (JACKSON, 2020, p. 23, tradução nossa). A ideia de animalizar, portanto, "não 
é incompatível com humanização: o que é comumente chamado de desumanização é, no fundo, mais corretamente interpretado como a violência da humanização ou o fardo da inclusão em uma humanidade universal racialmente hierarquizada" (JACKSON, 2020, p. 18, tradução nossa).

De todo modo, o racismo contra negros africanos e membros de comunidades tradicionais por ocidentais encontra suas origens, é claro, no período colonial. Inclusive, como ensina Francisco Bethencourt (2013), é comum encontrarmos esses indivíduos sendo retratados, em pinturas do século XVI, totalmente ou quase nus, em cenários selvagens, e circundados por animais diversos, como cabras, ovelhas, vacas, macacos, etc., tornando propositalmente - difícil distinguir entre uns e outros. Em mapas, igualmente, negros e animais eram retratados de modo ambíguo, confundindo-se uns com os outros.

Smith afirma, ainda, que "muitos colonizadores tanto tratavam escravos como menos humanos, quanto afirmavam, explicitamente, que africanos eram animais sem alma" (SMITH, 2011, p. 119, tradução nossa). Esses "animais nativos" (colonizados) eram, então, domesticados por "humanos ocidentais" (colonizadores), por meio de sua apropriação, familiarização e, finalmente, utilização (MBEMBE, 2001). E, do mesmo modo que afirmamos que "quebramos" um cavalo para domesticá-lo (do inglês, break a horse) destruindo seu espírito e o subjugando à nossa vontade -, no sul escravocrata norteamericano, havia homens chamados de "nigger breakers" ("quebradores" de negros), que eram responsáveis por "domar” os escravos considerados mais irreverentes (SPIEGEL, 1988).

A construção da ideia de raça tem como marco importante, como nos lembra Bethencourt (2013), a criação, por Karl Linnaeus, da famosa classificação de plantas que alcançava indivíduos humanos e não humanos, e que se tornou, para Michel Foucault (1966), o pilar da epistemologia do mundo clássico. E no cenário iluminista, em que a criação divina do mundo foi posta em questão - uma vez que o texto bíblico parecia incompatível com as novas evidências sobre o clima terrestre, a concepção newtoniana de universo, a existência de diferentes culturas, etc. -, colocou-se em questão, paralelamente, se seria possível traçar as origens de toda a humanidade a Adão e Eva, ou se certos povos possuiriam outra ancestralidade.

Nesse cenário, estudiosos monogenistas, nos séculos XVIII e XIX, passaram a sustentar que todos os seres humanos possuíam uma mesma procedência, enquanto poligenistas defendiam a existência de múltiplas origens. $\mathrm{O}$ debate se enfraqueceu a partir do 
darwinismo, mas não desapareceu por completo, abrindo espaço para uma hierarquização de indivíduos dentro da espécie humana:

Os sistemas de classificação baseavam-se naturalmente em estereótipos relativos a diferentes tipos de seres humanos; carregavam consigo uma presunção de rigorosa tabulação da natureza que afetava a maneira hierárquica como as variedades de seres humanos deviam ser descritas. $\mathrm{O}$ estudo científico multiplicou métodos e suposições para explicar as diferenças entre os humanos. Não era mais suficiente descrever características fenotípicas, bem como supostos graus de inteligência, hábitos e comportamento. Os crânios foram coletados e medidos; esqueletos foram comparados; e uma hierarquia de diferenças entre os seres humanos foi estabelecida de acordo com uma escala de proximidade ou distância com relação aos macacos. Essa estrutura geral de medidas [...] emprestou nova credibilidade às formas de classificação expressas por meio da noção de raça (BETHENCOURT, 2013, p. 250, tradução nossa).

Jackson (2020) afirma, em sentido similar, que no século XIX, a antropologia baseada na "Grande Cadeia do Ser" ("The Great Chain of Being" ou scala naturae) - a qual apresentava os seres vivos em uma escala hierárquica que colocava o Homem abaixo, apenas, dos anjos, e acima de todos os demais animais não humanos - passou a tirar medidas de animais humanos e não humanos, estabelecendo uma conexão entre símios e negros como verdade científica, hiperssexualizando mulheres negras, e denotando, a elas, um gênero e sexo distintos.

Nas palavras de Claire Jean Kim,

O posicionamento de homens sobre animais na Grande Cadeira do Ser resolveu uma questão, mas criou outras: que tipo de homem deveria ficar abaixo no ranking, mais próximo de animais? E seguindo os princípios da continuidade e da gradação, que tipo de criatura constitui o link entre os homens mais baixos e os animais mais elevados? (KIM, 2015, p. 35, tradução nossa)

Conclui-se, pois, que essa "nova disciplina na antropologia deu às ideologias racistas uma aparente credibilidade científica" (SMITH, 2011, p. 116).

\subsection{Os Outros e o mundo natural}

Para Keith Thomas (1988), o fenômeno descrito no subcapítulo anterior encontra suas origens teóricas na tentativa de pensadores do início da modernidade de traçar uma sólida linha divisória entre homens e animais, com o fim de justificar, moralmente, os hábitos de 
domesticação de animais não-humanos, de caça, de comer carne, da prática da vivissecção tornada corrente na ciência do fim do século $\mathrm{XVII}^{3}$-, etc.

Ocorre que esse esforço, segundo o autor, teria impactado não só as relações interespécies, como aquelas entre seres humanos, pois se a presença de certas qualidades era necessária para que a essência humana estivesse presente (como a racionalidade, a autoconsciência, a capacidade de linguagem, etc.), nem todo mundo seria capaz de integrar essa categoria. Com relação a negros, a língua diferente - considerada primitiva - e a religiosidade distinta da cristã, por exemplo, auxiliaram para que eles fossem retirados do âmbito de consideração moral ao qual pertenciam aqueles indivíduos considerados "normais", da mesma maneira que havia acontecido com animais não-humanos. Concluímos, a partir de Thomas, que a necessidade de se estabelecer uma categoria específica a ser integrada apenas por seres que cumpram requisitos antropocêntricos criados a partir de modelos que consideram como padrão ideal o europeu branco, hétero, do sexo masculino, e capaz, foi responsável por abrir espaço para uma exclusão de seres humanos do nosso âmbito de consideração moral.

De uma maneira um pouco diversa, Diane Leong sustenta não ser possível falar, propriamente, em uma exclusão de negros africanos da categoria de humanidade, mas sim, na criação de um novo tipo de humano e, mais do que isso, na criação de "um terceiro referencial (i.e., raça) na divisão animal-humano" (LEONG, 2021, p. 69, tradução nossa), estabelecendo, além de humanos e não-humanos, a categoria de quase-humanos.

De todo modo, comunidades tradicionais consideradas "exóticas", com sua linguagem "simples" e "primitiva" (JACKSON, 2020) - mito desconstruído, mais tarde, pelo antropólogo Franz Boas, ao estudar o rico idioma dos Inuit (KING, 2019) - e religiosidade distinta da cristã, eram vistas, como nos mostra Thomas (1988), como mais próximas do reino natural, do que como membros da categoria iluminista de humanidade. Ecoando Thomas, Kim afirma que "Homens atribuíram aos animais os impulsos naturais que eles mais temiam neles próprios - ferocidade, gula, sexualidade [...] Foi como uma observação com relação à natureza humana que o conceito de 'animalidade' foi elaborado" (KIM, 2015, p. 31, tradução nossa).

\footnotetext{
${ }^{3}$ Cf. DERBY, Joseph Wright of. An Experiment on a Bird in the Air Pump. Pintura a óleo sobre tela, $183 \times 244$ cm, 1768. Disponível em: https://www.nationalgallery.org.uk/paintings/joseph-wright-of-derby-an-experimenton-a-bird-in-the-air-pump. Acesso: 14 jul. 2021.
} 
Segundo Jackson, "Discursos sobre animais não-humanos e humanos animalizados são construídos um pelo outro; eles refletem [...] um ao outro com o propósito de produzir uma concepção idealizada e teleológica do "ser humano"” (JACKSON, 2020, p. 23, tradução nossa) Categorias de raça e espécie, portanto, "evoluíram em conjunto e são, em verdade, termos que se autorreforçam” (JACKSON, 2020, p. 8, tradução nossa).

Conclui-se, pois, que era essa aproximação dos negros com o mundo natural, e que levava à sua desumanização/animalização, o que importava, verdadeiramente, para sua exclusão da categoria de ser humano. Como preleciona Hannah Arendt:

O que os tornou [os negros] diferentes de outros seres humanos não foi, de modo algum, a cor da sua pele, mas o fato de que eles se comportavam como parte da natureza, que tratavam a natureza como seu mestre inconteste, que não haviam criado um mundo humano, uma realidade humana, e que, portanto, a natureza havia permanecido, em toda sua grandiosidade, a única realidade esmagadora que, em comparação, fazia com que eles parecessem espectros, irreais e fantasmagóricos. Eles eram, dessa maneira, seres humanos "naturais" que não possuíam as características específicas da condição humana, a realidade humana específica, de modo que quando europeus os massacravam, o faziam, de algum modo, sem se dar conta de que estavam cometendo assassinato (ARENDT, 1976, p. 192, tradução nossa).

E, para Achille Mbembe (2019), essa tradição de pensamento acaba por pressupor, equivocadamente, que existe uma divisão entre o mundo técnico dos humanos e mundo natural dos animais não-humanos.

\subsection{Zoológicos humanos}

Bons exemplos para a aproximação entre os fenômenos da racialização com o modo como tratamos animais não-humanos são os zoológicos, já que, criados no período colonial, tais espaços abrigavam, como objeto de exposição, tanto animais não-humanos, como os considerados "quase-humanos", ou "quase-animais", e que eram vistos como os Outros, os exóticos, simbolizando, ainda, o elo perdido darwiniano entre o mundo dos animais e o dos seres humanos (LOBO, 2015).

Nos séculos XIX e XX, foram expostos, nesse sentido, índios Galibi (originados de terras entre o Brasil e a Guiana Francesa), membros da etnia africana dos bosquímanos, da tribo Nyambi, pessoas com deficiência como o "homem-cachorro", etc. (BBC, 2011, não paginado). Saartjie Baartman, por exemplo, membro da etnia Khoisan e apelidada de "Venus 
Negra", era "uma mulher [...] com nádegas enormes, que havia sido trazida da África do Sul para a Europa no início do século dezenove pelo treinador de animais selvagens S. Réauz, para ser exibida em salões" (BOISSERON, 2018, p. 35, tradução nossa). O congolês pigmeu Ota Benga, por sua vez, foi exposto no Museu de História Natural de Nova Iorque para, depois, tornar-se se objeto de exibição no recém-aberto Zoológico do Bronx, onde dividia uma jaula com um orangotango (SMITH, 2011). Ainda, segundo nos contam Nicolas Bancel et al. (2000, não paginado):

A ideia de promover um espetáculo zoológico pondo em cena populações exóticas aparece paralelamente em vários países europeus ao longo da década de 70 do século passado. Inicialmente, na Alemanha, onde em 1874 Karl Hagenbeck, vendedor de animais selvagens e futuro promotor dos principais zoos europeus, decide apresentar, aos visitantes, ávidos de "sensações", nativos de Samoa e da Lapônia como populações "genuinamente naturais". O sucesso dessas primeiras exibições o conduz, a partir de 1876, a enviar um de seus colaboradores ao Sudão egípcio, a fim de trazer animais bem como nubianos, para renovar a "atração". Esses últimos tiveram sucesso imediato em toda a Europa, sendo apresentados sucessivamente em diversas capitais como Paris, Londres e Berlim.

No documentário da Canadian Broadcasting Corporation (CBC) "Trapped in a Human Zoo" (2016), somos apresentados aos relatos trazidos pelo diário de Abraham Ulrikab, um Inuk do Labrador que, junto à sua família e quatro outros Inuit, tornou-se atração nos shows etnográficos organizados por Karl Hagenbeck. No final do século XIX, Ulrikab, para pagar as dívidas de seu pai, e porque, tendo sido educado por missionários e frequentado escolas ocidentais, tinha curiosidade de ver a Europa, aceitou o convite de Hagenbeck para ser exposto no continente europeu. Muito rapidamente, contudo, se deu conta de seu erro, pois lhe pareceu, de algum modo, errado ser objetificado e exposto diante de multidões de pessoas curiosas, como se ele fosse algo, não alguém. Durante quase um ano de exposições, os Inuit dessa expedição foram adoecendo e morrendo, um a um, sem nunca mais retornarem ao seu lar.

Mbembe explora, de modo bastante interessante, o simbolismo que existe por trás dos zoológicos:

[...] a vida sob o signo da raça foi sempre equivalente à vida no zoológico. $\mathrm{Na}$ prática, dois ou três processos estão na base da construção de um zoológico. Primeiro, a abdução, captura, e aprisionamento de animais. Esses animais são tirados de seus habitats naturais por humanos que, tendo-os apreendido, não os matam, mas, em vez disso, os designam a um vasto e subdividido espaço de enclausuramento [...]. Nesse espaço de aprisionamento, os animais são privados de uma parte importante dos 
recursos que garantem a suas vidas qualidades naturais e fluidez. Eles são impossibilitados de se movimentar livremente. Para comer, eles são, a partir daí, inteiramente dependentes daqueles designados para seu cuidado diário. Em segundo, esses animais, então domados, são objeto de uma proibição implícita. Eles são impossibilitados de serem mortos, exceto em circunstâncias excepcionais e quase sempre com o propósito de consumo direto [...]. Em terceiro, esses animais cativos não são sujeitados a um regime estrito de domesticação. Um leão de zoológico não é tratado como um gato. Ele não compartilha da vida privada de humanos. Como os zoológicos não pertencem ao reino doméstico, a distância entre seres humanos e animais é mantida. De fato, sua exibição é permitida à distância, já que uma exibição só tem sentido na medida em que o espectador e o objeto sejam separados entre si. Por tudo isso, os animais vivem em um estado de suspensão. E com isso não são nem uma coisa, nem outra. Os negros exibidos em zoológicos humanos no Ocidente durante sua história não eram nem animais nem objetos. Pela duração de sua exibição, sua humanidade era suspensa (MBEMBE, 2019, p. 167, tradução nossa).

Não obstante negros e membros de comunidades tradicionais não serem, mais, expostos em zoológicos - como, notadamente, ainda ocorre com animais não-humanos de modo costumaz -, ainda assim podemos afirmar que "a negritude e a despersonificação de negros não são algo do passado" (BOISSERON, 2018, tradução nossa), e o processo de desumanização de africanos não terminou, como gostaríamos, com o fim de sua escravização, ou mesmo com o término do Apartheid, tal qual vimos acima. Como ensina Jackson, a emancipação de negros africanos é, então, "menos um evento decisivo, do que uma reorganização da estrutura da violência, um legado ambivalente, com ganhos e perdas, no qual a inclusão poderia funcionar indiscutivelmente como uma intensificação da sujeição racial” (JACKSON, 2020, p. 28, tradução nossa).

\section{RAÇA COMO CONSTRUÇÃO SOCIAL E CULTURAL}

Raça é, como vimos, uma construção histórica, cultural e social e não um conceito biológico e, nesse sentido, pode-se afirmar que só existe uma raça, a humana.

Arthur Gobinaeu (1816-1882) foi um grande teórico racista que atribuiu à raça ariana a posição de superioridade em relação à raça semita (LAFER, 2004, p. 68), o que fomentou uma política eugenista, posteriormente bastante desenvolvida nos EUA e criteriosamente aplicada pelo racismo biológico institucionalizado na Alemanha Nazista.

Claude Lévi-Strauss (1952) assevera que no presente estado do conhecimento científico, não há justificativa para afirmar que uma raça seja intelectualmente superior ou inferior a outra e que os grandes grupos étnicos, que constituem a humanidade, fizeram as 
suas próprias contribuições para a construção do patrimônio comum da humanidade. Assim, diferentes raças, na acepção cultural e social do termo, contribuíram para as civilizações e essa diversidade intelectual, estética e social de grupos étnicos não resultou de diferenças biológicas.

Afirma-se, portanto, que a diversidade cultural é um fenômeno natural que decorre da convivência entre as sociedades e que o conceito de humanidade abrange todas as formas de espécie humana, independentemente de raça ou civilização e, assim, a civilização mundial deveria refletir a coligação, em escala mundial, de culturas que preservam a sua originalidade, ou seja, deve-se fomentar a igualdade no contexto da diversidade.

Entretanto, há culturas que se consideram superiores às outras, o que revela uma atitude etnocêntrica, que tende a reservar o privilégio da humanidade a uma raça, cultura ou sociedade.

Nesse contexto, é salutar refletir sobre o conceito de etnicidade, que é usado para se referir a uma diversidade de grupos, de comunidades étnicas fundadas na solidariedade, revelando-se como uma construção social e como uma contingência histórica, que muitas pessoas concebem como uma parte importante e inalterável de sua identidade (MATHIAS, 2015).

$\mathrm{O}$ adjetivo étnico surgiu no século $\mathrm{XV}$, na língua inglesa, para se referir às características de grupos que não eram considerados judeus ou cristãos. No século XIX, o termo passou a ser usado para se referir a grupos que pertencem ou que têm as mesmas características linguísticas, religiosas, culturais ou sociais. No século XX, o termo passou a ser usado para se referir a migrantes ou a minorias. Apesar de haver um referencial histórico relativo ao termo étnico, etnicidade pode ser considerada como um termo recente, do começo dos anos 40, para se referir às características de uma pessoa ou de um grupo e que se distancia da perspectiva de raça, definida por marcadores biológicos (MATHIAS, 2015).

Assim, pode-se afirmar que a etnicidade está intrinsecamente ligada à identidade, no sentido de pertencimento de uma pessoa ou de um grupo a uma unidade estável, com características próprias, ou seja, tradição comum, forma comum de vida, cultura compartilhada, ancestrais comuns e solidariedade. Dessa forma, etnicidade refere-se à condição ou à consciência de pertencer a um grupo étnico e ao grau de conformidade dos membros de uma coletividade aos padrões culturais de um grupo. 
Por isso, propõe-se o termo etnia ao invés de raça, uma vez que aquela expressa uma realidade cultural na qual as pessoas que formam um determinado grupo étnico se baseiam em percepções comuns e em experiências espirituais compartilhadas; sendo que esta diz respeito aos atributos conferidos aos povos que compartilham dos mesmos traços biológicos. Nesse sentido, etnicidade ampliaria o contexto do pertencimento para a crença em uma identidade comum de determinados grupos.

No entanto, deve-se evitar que a etnização reflita o pensamento fechado, dominante e competitivo de determinados grupos como resposta à subordinação ao imperialismo universalista, o que desencadearia uma atitude etnocêntrica em contrário. Por isso, propõe-se a ideia da posetnicidade, com fundamento no multiculturalismo global, com a hibridização das culturas para além da mera tolerância (MATHIAS, 2015; KYMLICKA, 2014).

Por dizer respeito a um tema de interesse da humanidade, construiu-se um regime jurídico de Direito Internacional dos Direitos Humanos no sentido de proteger a diversidade, conforme será analisado a seguir.

\subsection{Do regime jurídico de Direito Internacional dos Direitos Humanos relativo às raças}

O objetivo do capítulo é analisar, no âmbito da UNESCO, o regime jurídico destinado a regular o instituto jurídico "raça". Preocupada com a preservação da dignidade da pessoa humana, após as atrocidades cometidas durante a Segunda Guerra Mundial, a comunidade internacional se reuniu, em cooperação, para instituir O Direito Internacional da Pessoa Humana, de acordo com os ideais da Carta de São Francisco, de 1945, bem como em consonância com a Declaração Universal dos Direitos Humanos, de 1948.

Com esse sentimento, a UNESCO promulgou a Declaração das Raças da Unesco, de 1950, reconhecendo que a humanidade é uma só e que todos os homens pertencem à mesma espécie, Homo sapiens, que se originou do mesmo tronco, sendo que as diferenças existentes entre os homens se devem a fatores evolutivos de diferenciação.

Admite-se, assim, que as semelhanças entre os homens são maiores do que as diferenças e, nesse sentido, as diferenças existentes são ínfimas se comparadas às semelhanças que decorrem do conjunto de constituição genética do homem.

A mesma Declaração define raça, em seu artigo $4^{\circ}$, como:

um grupo ou uma população caracterizada por certas concentrações, relativas quanto à frequência e à distribuição, de gens ou de caracteres físicos que, no 
decorrer dos tempos, aparecem, variam e muitas vezes até aparecem sob a influência de fatores de isolamento geográficos ou culturais. Cada grupo reflete de modo diferente as manifestações variáveis desses caracteres em populações diferentes. Sendo as nossas observações largamente afetadas pelos nossos preconceitos, somos levados a interpretar arbitrária e inexatamente toda variabilidade que se produz num grupo dado como uma diferença fundamental que o separa dos outros de modo decisivo.

Percebe-se que o termo raça não é normalmente empregado como na acepção dada pela Declaração da UNESCO e, assim, o documento sugere que o termo raça seja substituído por grupo étnico para se referir a grupos nacionais, religiosos, linguísticos ou culturais, que não coincidem necessariamente com grupos raciais.

Nesse aspecto, é relevante ressaltar que o termo etnicidade é usado para se referir a diversos grupos no decorrer da história da humanidade e tem relação com a construção de comunidades étnicas para a solidariedade perdida em estruturas de determinados grupos e para preencher as necessidades especiais de pertencimento (MATHIAS, 2015).

Nesse sentido, chama a atenção as palavras de Confúcio (551-478 a. C.), reproduzidas no artigo $9^{\circ}$ da Declaração das Raças: “A natureza dos homens é idêntica: são os costumes que os separam.”

Assim, não há comprovação científica de que as diferenças existentes entre os seres humanos são biológicas, genéticas e hereditárias. Ao contrário, elas decorrem da história cultural de cada grupo e derivam, portanto, do meio e, assim, raça seria mais um mito social do que um fenômeno biológico e, nesse contexto, o essencial seria a unidade da humanidade.

Em outro aspecto, a Declaração contextualiza o princípio da igualdade entre os homens, consignando que referido princípio não repousa na ideia de que todos os seres humanos são igualmente dotados, mas, ao contrário, repousa nas diferenças existentes entre os grupos étnicos.

Logo, não se pode propor uma classificação racial com base nas características físicas dos seres humanos, pois as diferenças genéticas não têm importância na determinação das diferenças culturais e sociais existentes entre grupos diferentes de Homo sapiens.

Por fim, a Declaração ressalta a ética da fraternidade universal nas pesquisas biológicas, com a demonstração de que o homem está inclinado, de forma inata, à cooperação, por ser um ser social que, para chegar ao desenvolvimento pleno de sua personalidade, necessita da troca com os seus semelhantes. 
A Declaração, ao final, enfatiza a ideia de que cada ser humano representa uma parcela da humanidade a qual está indissoluvelmente ligado.

Por sua vez, a Conferência Geral da Organização das Nações Unidas para a Educação, Ciência e Cultura adotou, em 27 de novembro de 1978, a Declaração sobre a Raça e os Preconceitos Raciais. Em seu preâmbulo, o documento ressalta os ideais da UNESCO, registrados no documento de sua constituição, em 1945, de respeito à pessoa humana, ao ideal democrático da dignidade e à igualdade. Além disso, o preâmbulo ainda expressa a necessidade de se erradicar o flagelo do racismo, decorrente dos processos de colonização, ou seja, a necessidade de se concretizar o processo de descolonização.

Ainda na fase preambular, o documento ressalta que a diversidade entre as culturas é considerada patrimônio comum da humanidade, além de ressaltar a unidade intrínseca à raça humana, com a igualdade fundamental de todos os seres humanos e de todos os povos, como fundamento da ética e da ciência, ressaltando sua indignação em relação aos atentados contra a dignidade humana como o racismo, a discriminação racial, o colonialismo e o apartheid, dentre outros.

Nesse contexto, o documento inicia o articulado consignando a igualdade entre todos os seres humanos, que pertencem a mesma espécie e são parte integrante da humanidade, mas que têm o direito de preservar sua diversidade, que não pode justificar o preconceito racial, práticas discriminatórias, nem servir de fundamento para a política do apartheid.

$\mathrm{O}$ documento ainda ressalta, em seu artigo 1.5 que as diferenças culturais existentes entre os povos não podem servir de pretexto para a hierarquização de nações ou povos e que qualquer teoria que invoque a superioridade ou a inferioridade intrínseca de grupos raciais ou étnicos não tem base científica e é contrária aos princípios morais e éticos da humanidade (artigo 2.1).

No contexto da igualdade e da diversidade, o documento prevê, em seu artigo $3^{\circ}$ que a discriminação racial é incompatível com "as exigências de uma ordem internacional justa e que garanta o respeito aos direitos humanos."

Dando continuidade à análise do regime jurídico relativo à raça, é relevante destacar que, em 2002, a UNESCO aprovou a Declaração Universal sobre Diversidade Cultural consignando o princípio da diversidade cultual, como patrimônio comum da humanidade, que deve ser respeitada no contexto do pluralismo cultural e que deve ser considerada como fator de desenvolvimento humano. 
A Declaração ainda ressaltou que a garantia da diversidade cultural está inserida no contexto dos direitos humanos e, nesse sentido, não pode ser invocada para justificar sua violação. O documento ainda ressalta que os direitos culturais, marco propício da diversidade cultural, são parte integrante dos direitos humanos (Artigo 5).

Vale ressaltar que, no preâmbulo, a Declaração define cultura como:

o conjunto de traços distintivos espirituais e materiais, intelectuais e afetivos que caracterizam uma sociedade ou um grupo social e que abrange, além das artes e das letras, os modos de vida, as maneiras de viver juntos, os sistemas de valores, as tradições e as crenças. ${ }^{4}$

Com a análise dos documentos internacionais acima, foi possível perceber que existe um regime jurídico destinado à proteção da igualdade, da diversidade e da não discriminação, bem como para delinear o conceito de raça.

Paradoxalmente, a comunidade internacional comporta-se no sentido de classificar os seres humanos em raças, sob a perspectiva biológica, o que não tem respaldo científico. Nesse sentido, a discussão a respeito do crime de racismo vem à tona, o que será contextualizado no capítulo seguinte.

\subsection{Racismo: uma análise do caso Ellwanger}

O objetivo do capítulo é analisar o racismo a partir do caso Ellwanger, julgado pelo Supremo Tribunal Federal ${ }^{5}$, em 2003, no HC 82.424-2, do Rio Grande do Sul, que refere-se a racismo e raça, o que também foi abordado no Parecer elaborado por Celso Lafer sobre o caso (2004).

O caso diz respeito à prática do crime de racismo, tipificado como crime imprescritível no Brasil, no artigo $5^{\circ}$, XLII da Constituição Federal de 1988. No parecer elaborado por Celso Lafer (2004) houve a explanação a respeito do significado de raça e do crime de racismo, o que é relevante para o tema discutido no artigo.

\footnotetext{
${ }^{4}$ Definição em consonância com as conclusões da Conferência Mundial sobre as Políticas Culturais (MONDIACULT, México, 1982), da Comissão Mundial de Cultura e Desenvolvimento (A Nossa Diversidade Criativa, 1995) e da Conferência Intergovernamental sobre Políticas Culturais para o Desenvolvimento (Estocolmo, 1998). Informação http://www.unesco.org/new/fileadmin/MULTIMEDIA/HQ/CLT/diversity/pdf/declaration_cultural_diversity_pt. pdf. Acesso em: 18 set. 2021.

${ }_{5}^{5}$ Disponível em: https://redir.stf.jus.br/paginadorpub/paginador.jsp?docTP=AC\&docID=79052. Acesso em: 18 set. 2021.
} 
O Sr. Ellwanger alegava que se judeu não pode ser considerado raça, não havia como se alegar a prática do crime de racismo e o parecer demonstrou que, embora exista apenas uma raça, a humana, isso não afasta a prática do crime de racismo, que tem conotações culturais, conforme será analisado a seguir.

A esse respeito, A Declaração sobre Raça e Preconceito Racial da UNESCO, conforme já foi salientado, preocupa-se com a prática do racismo ao estabelecer que todos os seres humanos pertencem a uma única espécie, não excluindo o direito à diversidade de indivíduos e grupos $\left(\operatorname{artigo} 1^{\circ}\right.$ ). Além disso, o documento afirma que não há fundamentação científica para as teorias que preconizam a superioridade e a inferioridade de determinados grupos étnicos. Por isso, o documento consigna que a prática do racismo reside nas ideologias racistas (artigo $2^{\circ}, 2$ ) e nega o conceito de raça ao afirmar a unidade da espécie humana (Artigo $1^{\circ}$ ), estabelecendo que a erradicação do racismo, da discriminação racial e do preconceito racial requer a negação do estereótipo, das figuras parciais, unilaterais ou tendenciosas de indivíduos ou de vários grupos humanos (Artigo 5º 3 ).

Nesse contexto, pode-se afirmar que raça não é um conceito biológico, mas sim uma realidade social, uma das formas de se identificar pessoas de acordo com perspectivas particulares (LAFER, 2004, p. 35). E, nesse sentido, o racismo é uma construção social e cultural, consequência da naturalização das diferenças que contraria a ideia de que a humanidade é uma só, as culturas é que são plurais (LAFER, 2004, p. 81). Assim, o problema não está na existência ou não de raças, mas no sentido que se dá ao termo como construção social positiva ou negativa.

De acordo com esse raciocínio, interpretar a prática do racismo a partir do conceito de raça, refutado pelo sequenciamento do genoma humano, conduziria ao esvaziamento completo do crime de racismo no Brasil e do regime jurídico do Direito Internacional dos Direitos Humanos destinado ao combate ao racismo. Assim, embora exista apenas uma raça, a humana, não se pode descartar o crime de racismo praticado contra determinados grupos como os judeus, os negros, os indígenas e outros grupos. Concluir de forma diversa a este raciocínio seria contrariar a ideia de que, na interpretação dos direitos humanos, deve-se favorecer, sempre, o melhor conteúdo do direito (LAFER, 2004, p. 57), promovendo-se a dignidade humana.

Logo, a discussão da prática do racismo não deve se centrar no conceito de raça, mas sim nas práticas discriminatórias do racismo, que decorrem de uma construção histórica, 
política e cultural, e que está pautado na ideia de que a humanidade está dividida em raças, que existem raças superiores e inferiores e que as superiores têm o direito de dominar as inferiores (BOBBIO, 2012).

\section{CONSIDERAÇÕES FINAIS}

Como foi possível perceber, o fim da escravização de negros africanos ou de práticas segregacionistas legitimadas pelo Estado não significou o término do racismo que, diversamente, segue como fator de violência estrutural em nossa sociedade.

E, apesar de a codificação do genoma humano ter revelado, com certeza científica, que não existem, dentro da espécie humana, raças distintas, sendo, em tese, mais apropriada a utilização da expressão "etnia", o fato é que a ideia de raça, como fator de discriminação de indivíduos humanos é, ela própria, uma construção histórica e cultural, que nada tem a ver com quaisquer fatores biológicos.

É, por esse motivo, fundamental que conheçamos essa distinção teórica no âmbito da biologia e da sociologia, e o modo como a comunidade internacional comporta-se no sentido de se utilizar desse tipo de classificação, para que não nos tornemos cegos para esse tipo de violência, e para os fatores por ela responsáveis. Não devemos nos tornar, para utilizar uma expressão dos estudos críticos raciais, collorblind, sob o risco de invisibilizarmos, na mesma medida, as violações a indivíduos considerados inferiores por não se adequarem ao padrão humano construído no contexto do humanismo iluminista.

Em outras palavras, quer queiramos, quer não, raças humanas, ainda que não existam na biologia, na prática, não só existem, como sujeitam incontáveis indivíduos a discriminações e violações dos mais diversos tipos. Contextualizar as ideias de raça e etnia, seja histórica, biológica, ou juridicamente, torna-se, nessa medida, fundamental para tornar o debate em torno do racismo estrutural mais lúcido e coerente.

\section{REFERÊNCIAS BIBLIOGRÁFICAS}

ANGELOU, Maya. I Know Why the Caged Bird Sings. Londres: Hachette Digital, 1969.

ARENDT, Hannah. The Origins of Totalitarianism. Nova York: A Harvest Book, 1976. 
BANCEL, Nicolas; BLANCHARD, Pascal; LEMAIRE, Sandrine. Os jardins zoológicos humanos. Le Monde Diplomatique Brasil, 01 ago. 2000. Disponível em: https://diplomatique.org.br/os-jardins-zoologicos-humanos/. Acesso: 29 mar. 2021.

BBC NEWS BRASIL. Exposição relembra shows étnicos com humanos 'exóticos' na Europa. 01 dez. 2011. Disponível em:

https://www.bbc.com/portuguese/noticias/2011/12/111201_galeria_shows_etnicos_df. Acesso: 29 mar. 2021.

BETHENCOURT, Francisco. Racisms: From the Crusades to the Twentieth Century. Oxford: Princeton University Press, 2013.

BOBBIO, Norberto. Elogio da serenidade e outros escritos morais. $2^{\mathrm{a}}$ ed. Trad. Marco Aurélio Nogueira. São Paulo: UNESP, 2012.

BOISSERON, Bénédicte. 2018. Afro-Dog: Blackness and the Animal Question. New York: Columbia University Press.

FOUCAULT, Michel. Les mots et les choses: une archéologie des sciences humaines. Paris: Éditions Gallimard, 1966.

JACKSON, Zakiyyah Iman. Becoming Human: Matter and Meaning in an Antiblack World. Nova York: New York University Press, 2020.

KILOMBA, Grada, Plantation Memories: Episodes of Everyday Racism. 2. ed. Münster: Unrast, 2010.

KIM, Claire Jean. Dangerous Crossings: Race, Species, and Nature in a Multicultural Age. Nova York: Cambridge University Press, 2015.

KING, Charles. Gods of the Upper Air: How a Circle of Renegade Anthropologists Reinvented Race, Sex and Gender in the Twentieth Century. Nova York: Doubleday, 2019.

KYMLICKA, Will. Multiculturalismo: o sucesso, o fracasso e o futuro. Interfaces Brasil/Canadá. Revista Brasileira de Estudos Canadenses, v. 14, n. 1, pp. 123-174, 2014. Disponível em: https://periodicos.ufpel.edu.br/ojs2/index.php/interfaces/article/view/6788. Acesso em: 08 jul. 2021.

LAFER, Celso. Parecer: O caso Ellwanger: anti-semitismo como crime da prática do racismo. Revista de Informação Legislativa, v. 41, n. 162, pp. 53-90, abr./jun. 2004. Disponível em https://www2.senado.leg.br/bdsf/bitstream/handle/id/948/R162-

08.pdf?sequence $=4 \&$ is Allowed=y. Acesso em: 18 set. 2021 .

LEONG, Diana. An(im)alogical Thinking: Contemporary Black Literature and the Dreaded Comparison. In: MCHUGH, Susan et al. (eds.). The Palgrave Handbook of Animals and Literature. Cham: Palgrave McMillian, 2021. 
LÉVI-STRAUSS, Claude. Race and history. Paris: UNESCO, 1952. Disponível em https://unesdoc.unesco.org/ark:/48223/pf0000002896?posInSet=1\&queryId=9f753f59-4eac4ffb-8e65-0e8972075254. Acesso em: 13 jul. 2021.

LOBO, Liliao3 Ferreira. Os infames da história: pobres, escravos e deficientes no Brasil. $1^{\text {a }}$ ed. Rio de Janeiro: Lamparina, 2015, pp. 63-65.

MBEMBE, Achille. Necropolitics. Trad. Steven Corcoran. Durhan: Duke University Press, 2019

MBEMBE, Achille. On the Postcolony. Califórnia: University of California Press, 2001.

MATHIAS, Bos. Ethnicity and ethinic groups: historical aspects. International Encyclopedia of the Social \& Beharioral Sciences, v. 8, pp. 136-141, 2015. Disponível em https://www.researchgate.net/profile/Boes-

Mathias/publication/304193654_Ethnicity_and_Ethnic_Groups_Historical_Aspects/links/5cd fc105299bf14d95a398a5/Ethnicity-and-Ethnic-Groups-Historical-

Aspects.pdf?origin=publication_detail. Acesso em: 13 jul. 2021.

SMITH, David Livingstone. Less than Human: Why We Demean, Enslave, and Exterminate Others. Nova York: St. Martin's Press, 2011.

SPIEGEL, Marjorie. The Dreaded Comparison: Human and Animal Slavery. Londres: Heretic Books, 1988.

THOMAS, Keith. O homem e o mundo natural: mudanças de atitude em relação às plantas e aos animais, 1500-1800. Trad. João Roberto Marins Filho. São Paulo: Companhia das Letras, 1988.

TRAPPED IN A HUMAN ZOO. Direção: Guilhem Rondot e Chris Goldade. Produção: Roch Brunette. Canadá: Canadian Broadcasting Corporation, 2016 (60 min.). 